\title{
FORMULATION AND IN VITRO EVALUATION OF MATRIX TABLETS OF METOCLOPRAMIDE HYDROCHLORIDE
}

\author{
S. JAYA*, DIVYA. S \\ Department of Pharmaceutics, Anurag Pharmacy College, Ananthagiri, Kodad, Suryapet 508206, Telangana, India \\ Email: jayamay24@gmail.com
}

Received: 27 Oct 2018, Revised and Accepted: 19 Nov 2018

\section{ABSTRACT}

Objective: The purpose of present study was to formulate oral sustained release matrix tablet of metoclopramide hydrochloride and to evaluate the effect of varying concentrations of hydrophobic and hydrophilic polymers on drug release.

Methods: Drug-excipients compatibility studies were carried out by using Fourier transform infrared spectroscopy (FTIR). The matrix tablets were prepared by direct compression technique using Xanthan gum and ethyl cellulose alone and in combination as release retardant. Dicalcium phosphate was used as diluent. The prepared matrix tablets were evaluated for their physicochemical parameters such as weight variation, hardness, friability, content uniformity and in vitro drug release studies were performed using USP-type II (paddle) dissolution apparatus.

Results: Pre and post compression parameters were evaluated and all the parameters were found within the limit. The matrix tablets prepared with xanthan gum and combination of xanthan gum and ethyl cellulose were retarded the drug release upto $12 \mathrm{~h}$. Ethyl cellulose alone could not control the drug release for $12 \mathrm{~h}$. The Formulation with drug to xanthan gum (1:1.5), released $97.62 \%$ of drug in 12 h. The kinetic treatment showed that the release of drug follows zero order kinetics $\left(\mathrm{R}^{2}=0.985\right)$. Korsmeyer and Peppas equation values of $\mathrm{n}$ were found to be in the range of 0.40-0.56, indicating that the drug release mechanism was diffusion.

Conclusion: Matrix tablet is the simple, efficient and economic method to sustain the release of metoclopramide to prevent extrapyramidal side effects.

Keywords: Matrix tablets, Metoclopramide hydrochloride, Xanthan gum

(C) 2019 The Authors. Published by Innovare Academic Sciences Pvt Ltd. This is an open access article under the CC BY license (http://creativecommons.org/licenses/by/4.0/) DOI: http://dx.doi.org/10.22159/ijap.2019v11i2.30506

\section{INTRODUCTION}

Metoclopramide hydrochloride is a potent antiemetic drug, used to treat emesis caused due to chemotherapy in cancer patients [1]. Metoclopramide is 4-amino-5-chloro-N-[2-(diethyl amino) ethyl amino) ethyl]-2-methoxy benzamide mono hydrochloride mono hydrate. It antagonizes $\mathrm{D}_{2}$ dopamine receptors in chemoreceptor trigger zone (CTZ) of the medulla. It exerts gastroprokinetic (increases motility of the stomach and duodenum) effect by antagonizing dopamine mediated relaxation effect on gastro intestinal smooth muscle results to an increase of gastric empting into the intestine there by preventing nausea and vomiting. Metoclopramide hydrochloride is a freely soluble drug and is rapidly absorbed from the gastrointestinal tract [2, 3]. It has short and variable biological half-life i.e. $5 \pm 1 \mathrm{hr}$ [4]. It is usually administered in per oral dose of 10-15 $\mathrm{mg}$ four times a day. This frequent administration results blood level fluctuations leads to extrapyramidal symptoms [5].

Oral administration is the most common and preferred route for delivery of most therapeutic agents. The popularity of oral route is attributed to ease of administration, accurate dosing, cost effective, flexibility in design of dosage form and high patient compliance. Sustained release dosage forms are designed to release the drug at a slow rate by maintaining a constant drug level in blood for a specified period of time with minimum side effects, optimized therapy and better patient compliance. Matrix technologies have often proven popular among the oral controlled drug delivery technologies because of their simplicity, ease in manufacturing, high level of reproducibility, stability of the raw materials, ease of scaleup and process validation $[6,7]$. In a Matrix system the drug is dispersed as solid particles within a porous matrix former of a hydrophilic or hydrophobic polymer [8]. Drug release in matrix tablets is controlled by the polymer properties and its structure. Natural gums are inert and non toxic. Xanthan gum is a natural, biosynthetic, edible gum, high molecular weightgum. Xanthan gum is an extracellular polysaccharide produced by fermentation of carbohydrate with Xanthomonas Compestris bacteria, is hydrophilic swellable polymer. It is a long chained polysaccharide with large number of tri saccharides side chains. The side chains are composed of two mannose units and one glucuronic acid unit. It develops a weak structure in water which creates high viscosity solutions at low concentration. Ethyl cellulose is hydrophobic synthetic polymer, is a derivative of cellulose $[9,10]$.

The aim of this study was to prepare matrix tablets of metoclopramide hydrochloride using varying proportions of the xanthan gum and ethyl cellulose to achieve sustained release of drug. Sustained release of the drug would prevent the extrapyramidal side effects of the drug on the central nervous system and improve the patient compliance. The probable additive effect of mixture of xanthan gum and ethyl cellulose on retarding drug release was also studied.

\section{MATERIALS AND METHODS}

\section{Materials}

Metoclopramide hydrochloride was purchased from Yarrow chemical Ltd., Mumbai (India). Xanthan gum, ethyl cellulose, dicalcium phosphate, magnesium stearate and talc were purchased from Aman scientific traders Vijayawada (India). All other reagents used were of analytical grade.

\section{Methods}

Analytical method for calibration curve of metoclopramide hydrochloride

Maximum wavelength of metoclopramide hydrochloride was found to be $272 \mathrm{~nm}$ using UV-visible spectroscopy. Standard solution $(100 \mu \mathrm{g} / \mathrm{ml})$ was prepared from stock solution $(1 \mathrm{mg} / \mathrm{ml})$ with $\mathrm{p}^{\mathrm{H}} 6.8$ phosphate buffer. Aliquotes of standard drug solution ranging from 0.4 to $2.4 \mathrm{ml}$ were transferred into $10 \mathrm{ml}$ volumetric flask and were diluted up to the mark with $\mathrm{p}^{\mathrm{H}} 6.8$ phosphate buffer. The absorbance of each solution was measured at $272 \mathrm{~nm}$ against $\mathrm{p}^{\mathrm{H}} 6.8$ phosphate buffer. A plot of concentration of drug versus absorbance was plotted. The linear regression analysis was applied. The standard regression equation for metoclopramide hydrochloride obtained was $y=0.037 x+0.003$ with a coefficient of regression $\left(R^{2}\right)$ of 0.999 . 


\section{Drug-excipient compatibility study}

Compatibility study of metoclopramide hydrochloride with the excipients was determined by fourier transform infrared (FTIR) spectroscopy.

\section{Formulation design}

Dose calculation of the sustained release formulation [11]

Total dose $=$ usual dose (D) + maintenance dose (Dm)

Pharmacokinetic studies showed that a dose of $10 \mathrm{mg}$ of metoclopramide hydrochloride produces an effective blood level concentration within $0.5 \mathrm{~h}$ with the mean half-life of $4 \mathrm{~h}$.

The elimination rate constant

$$
==0.1732 \mathrm{~h}-1
$$

The available rate $\mathrm{R}=\mathrm{k} \times \mathrm{D}$

$$
=0.1732 \times 10=1.732 \mathrm{mg} / \mathrm{h} \text {. }
$$

Where, $\mathrm{D}$ is the usual dose of the drug.

But $\mathrm{D}$ is corrected $=\mathrm{D}-(\mathrm{R} \times \mathrm{tp})=10-(1.732 \times 0.5)=9.134 \mathrm{mg}$.

Where, tp is the time period required to achieve a peak plasma concentration.
The maintenance dose, $\mathrm{Dm}=\mathrm{R} \times \mathrm{h}$

$=1.732 \times 12=20.784 \mathrm{mg}$.

Where, $\mathrm{h}$ is the number of hours for which sustained action is desired.

Thus the total dose of the drug was calculated by the following equation

Therefore total dose corrected $=\mathrm{D}$ corrected $+\mathrm{Dm}$

$$
=9.134+20.784=29.918 \mathrm{mg}
$$

Total dose corrected $\equiv 30 \mathrm{mg}$

\section{Preparation of matrix tablets}

Matrix tablets of metoclopramide hydrochloride were prepared by direct compression technique. All the ingredients were individually screened through sieve no. 60, except glidant and lubricant. Required quantities of metoclopramide hydrochloride, polymer, diluent were accurately weighed according to the composition shown in table 1 and mixed in a polybag for about 30 to $45 \mathrm{~min}$. The obtained blend was lubricated with talc and magnesium stearate for another $5 \mathrm{~min}$ and then the resultant mixture was directly compressed into tablets with $8 \mathrm{~mm}$ dome-shaped punches using 12station rotary tablet machine (CEMACH, Ahmedabad, India). The

\begin{tabular}{|c|c|c|c|c|c|c|c|c|c|}
\hline \multirow[t]{2}{*}{ Ingridients per tablets (mg) } & \multicolumn{9}{|c|}{ Composition (mgs) of the prepared formulation } \\
\hline & F1 & F2 & F3 & F4 & F5 & F6 & F7 & F8 & F9 \\
\hline Metoclopramide & 30 & 30 & 30 & 30 & 30 & 30 & 30 & 30 & 30 \\
\hline Xanthan gum (XG) & 30 & 45 & 60 & - & - & - & - & - & - \\
\hline Ethyl cellulose (EC) & - & - & - & 30 & 45 & 60 & - & - & - \\
\hline $\mathrm{XG}+\mathrm{EC}$ & - & - & - & - & - & - & 30 & 45 & 60 \\
\hline Di calcium phosphate & 180 & 165 & 150 & 180 & 165 & 150 & 180 & 165 & 150 \\
\hline Magnesium stearate & 5 & 5 & 5 & 5 & 5 & 5 & 5 & 5 & 5 \\
\hline Talc & 5 & 5 & 5 & 5 & 5 & 5 & 5 & 5 & 5 \\
\hline Tablet weight & 250 & 250 & 250 & 250 & 250 & 250 & 250 & 250 & 250 \\
\hline
\end{tabular}
final weight of the tablet was adjusted to $250 \mathrm{mg}$.

Table 1: Composition of matrix tablets of metoclopramide hydrochloride

\section{Micromeritic properties of the blended powder}

\section{Angle of repose}

The angle of repose of powder blend was determined by the fixed funnel method. The accurately weighed powder was taken in a funnel. The height of the funnel was adjusted in such a way that the tip of the funnel just touched the apex of the heap of the powder. The powder was allowed to flow through the funnel freely onto the surface. The diameter of the powder cone was measured and the angle of repose was calculated using the following equation [12].

$$
\tan \theta=\frac{h}{r}
$$

Where, $\theta=$ angle of repose,

$\mathrm{h}=$ height of the pile,

$r=$ radius of the pile base

\section{Bulk density and tapped density}

A quantity of $2 \mathrm{~g}$ of powder from each formula, previously lightly shaken to break any agglomerates formed was introduced into a 10 $\mathrm{ml}$ measuring cylinder. After the initial volume was observed then calculate bulk density using the following formula [12].

$$
\text { Bulk density }=\frac{\text { weight of the powder }}{\text { bulk volume }}
$$

The cylinder was allowed to fall under its own weight onto a hard surface from the height of $2.5 \mathrm{~cm}$ at 2 -second intervals. The tapping was continued until no further change in volume was noted. Tapped density was calculated using the following formula [12].

$$
\text { tapped density }=\frac{\text { weight of the powder }}{\text { tapped volume }}
$$

\section{Compressibility index}

The compressibility index of the powder blend was determined by Carr's compressibility index [12].

$$
\text { Carr's index }=\frac{\text { tapped density }- \text { bulk density }}{\text { tapped density }} \times 100
$$

\section{Evaluation of matrix tablets}

The tablets were evaluated for their physical properties like weight variation, hardness, and friability.

\section{Weight variation}

20 tablets of each formulation were weighed using an electronic weighing balance. The average weight was calculated and individual tablet weight was compared with average weight [12].

\section{Hardness and friability}

The hardness of three tablets was measured by Monsanto hardness tester. Hardness of tablets was measured in terms of $\mathrm{kg} / \mathrm{cm}^{2}$ Friability of tablets was measured by using Roche friabilator. Ten tablets were accurately weighed and placed in the friabilator and operated for 100 revolutions. The tablets were dedusted and reweighed and friability was calculated using the following equation [14].

$$
\text { Friability }=\frac{\text { Initial weight }- \text { Final weight }}{\text { Initial weight }} \times 100
$$

\section{Uniformity of drug content}

10 Tablets were weighed from each formulation and triturated in the mortar to a fine powder. Powder equivalent to $30 \mathrm{mg}$ of metoclopramide was extracted in $100 \mathrm{ml}$ of $\mathrm{p}^{\mathrm{H}} 6.8$ phosphate buffer and the liquid was filtered. The drug content was determined by measuring the absorbance at $272 \mathrm{~nm}$ (using UV-Visible spectrophotometer, Lab India) after appropriate dilution with $\mathrm{p}^{\mathrm{H}} 6.8$ phosphate buffer. The drug content was determined by calibration curve. 


\section{In vitro dissolution study}

The in vitro dissolution study of matrix tablets of metoclopramide was performed using USP type II (paddle) dissolution apparatus (DBK) at a rotational speed of $50 \mathrm{rpm}$. In order to simulate gastrointestinal transit conditions, the tablets were subjected to different dissolution media. The dissolution medium consists of 900 $\mathrm{ml}$ of $\mathrm{p}^{\mathrm{H}} 1.2$ buffer for the first two hours and $\mathrm{p}^{\mathrm{H}} 6.8$ phosphate buffer for the next ten hours. The dissolution medium was maintained at a temperature of $37 \pm 0.5^{\circ} \mathrm{C}$. At predetermined time intervals, $5 \mathrm{ml}$ sample of the solution was withdrawn from the dissolution apparatus and the samples were replaced with fresh dissolution medium. The collected samples were filtered through a $0.45 \mu \mathrm{m}$ membrane filter and diluted to a suitable concentration with $\mathrm{p}^{\mathrm{H}} 6.8$ phosphate buffer. An absorbance of these solutions was measured at $272 \mathrm{~nm}$. Cumulative percentage of drug release was calculated using equation obtained from a calibration curve [15].

\section{Kinetic analysis of drug release data}

The drug release data was fitted to zero order and first order to know the order of reaction. To study the mechanism of drug release from the formulations the release data were fitted to the following equations.

Higuchi model: $\mathrm{Q}=\mathrm{K}_{\mathrm{H}} \mathrm{t}^{1 / 2}$

Korsmeyer-Peppas model: $Q / Q_{t}=K_{K P} t^{n}$
Where $Q$ is amount of drug release at time $t, Q \mathrm{~T}$ is the total amount of drug release and $n$ is the diffusional exponent that characterizes the mechanism of drug release. The values of the coefficient were calculated using the regression analysis between $\log Q / Q_{\mathrm{T}}$ and $\log$ time. The diffusional exponent $n$ value was obtained from the slope of the regression equation and $\mathrm{K} \mathrm{KP}$ was calculated from antilog of the intercept value.

If the value of $n$ for a cylinder is $<0.45$ it suggests the Fickian release (diffusion controlled), if $n>0.45$ and $<0.89$ it is non-Fickian release (diffusion and polymer relaxation), 0.89 is case II release (only relaxation and swelling) and $>0.89$ it suggests super case II release (relaxation and erosion) for swellable systems

For cylindrical systems like tablets, the $\mathrm{n}$ values of 0.45 and 0.89 represent pure diffusion or erosion release respectively [16].

\section{RESULTS AND DISCUSSION}

\section{Powder characterization}

The powder mixture of all the formulations were evaluated for angle of repose, bulk density, tapped density, compressibility index, and their values were shown in table 2. Angle of repose and compressibility index for all the formulations were found to be less than $30^{\circ}$ and less than $17.13 \%$, indicated that powder mixture has good flow properties.

Table 2: Micromeritic properties of formulation blends

\begin{tabular}{|c|c|c|c|c|c|}
\hline Formulation & Bulk density $\left(\mathrm{gm} / \mathrm{cm}^{3}\right)^{*}$ & Tapped density $\left(\mathrm{gm} / \mathrm{cm}^{3}\right)^{*}$ & Compressibility index (\%) & Hausners ratio & Angle of repose $\left({ }^{\circ}\right)$ \\
\hline F1 & $0.33 \pm 0.03$ & $0.40 \pm 0.01$ & 17.13 & 1.21 & 25.40 \\
\hline $\mathrm{F} 2$ & $0.32 \pm .03$ & $0.39 \pm 0.02$ & 17.81 & 1.22 & 24.26 \\
\hline F3 & $0.35 \pm 0.01$ & $0.40 \pm 0.02$ & 12.50 & 1.14 & 26.15 \\
\hline $\mathrm{F} 4$ & $0.31 \pm 0.03$ & $0.37 \pm 0.03$ & 16.22 & 1.19 & 26.82 \\
\hline F5 & $0.32 \pm 0.02$ & $0.39 \pm 0.03$ & 17.18 & 1.21 & 28.30 \\
\hline F6 & $0.31 \pm 0.01$ & $0.38 \pm 0.02$ & 17.63 & 1.21 & 25.34 \\
\hline F7 & $0.35 \pm 0.03$ & $0.40 \pm 0.03$ & 14.11 & 1.16 & 28.18 \\
\hline F8 & $0.32 \pm 0.01$ & $0.38 \pm 0.02$ & 15.00 & 1.18 & 28.24 \\
\hline F9 & $0.34 \pm 0.03$ & $0.42 \pm 0.02$ & 17.38 & 1.21 & 27.82 \\
\hline
\end{tabular}

${ }^{*}$ All values are expressed as mean $\pm \mathrm{SD}, \mathrm{n}=3$

\section{Evaluation of physical parameters}

Sustained release matrix tablets of metoclopramide hydrochloride were prepared by direct compression technique employing varying concentrations of xanthan gum (F1,F2, F3), ethyl cellulose (F4,F5,F6) and their mixture-xanthan gum plus ethyl cellulose (F7,F8, F9). All the tablets were found to be non-disintegrating in $0.1 \mathrm{~N}$ hydrochloric acid and $\mathrm{p}^{\mathrm{H}} 6.8$ phosphate buffer except formulations prepared with ethyl cellulose. The physical properties of metoclopramide matrix tablets were given in table 3 . In weight variation test the percentage deviation of all tablet formulations was found to be within the pharmacopoeial acceptable limit. The hardness of the tablets was found to be in the range of $5.05 \pm 0.15$ to $5.87 \pm 0.08 \mathrm{~kg} / \mathrm{cm}^{2}$.

The percentage weight loss in the friability test was found to be below $1 \%$ in all the cases indicated that all the tablets had good mechanical strength. The drug content in all the batches was measured by double beam UV spectrophotometer (LABINDIA). The content of metoclopramide hydrochloride was found to be in the range of 98.33 to $99.98 \%$.

Table 3: Physical properties of metoclopramide hydrochloride matrix tablets

\begin{tabular}{|c|c|c|c|c|}
\hline Formulation & Weight variation (mg) & Hardness $\left(\mathrm{kg} / \mathrm{cm}^{2}\right)^{*}$ & Friability (\%) & Content uniformity (\%) \\
\hline F1 & $248.80 \pm 1.40$ & $5.63 \pm 0.08$ & 0.48 & 99.80 \\
\hline $\mathrm{F} 2$ & $248.95 \pm 1.57$ & $5.87 \pm 0.08$ & 0.40 & 98.64 \\
\hline F3 & $249.10 \pm 1.62$ & $5.98 \pm 0.14$ & 0.36 & 99.66 \\
\hline $\mathrm{F} 4$ & $248.95 \pm 1.56$ & $5.05 \pm 0.15$ & 0.68 & 99.98 \\
\hline F5 & $249.05 \pm 1.61$ & $5.13 \pm 0.12$ & 0.64 & 99.05 \\
\hline F6 & $248.15 \pm 1.46$ & $5.20 \pm 0.14$ & 0.61 & 98.33 \\
\hline F7 & $249.15 \pm 1.57$ & $5.52 \pm 0.08$ & 0.52 & 98.92 \\
\hline F8 & $249.15 \pm 1.50$ & $5.73 \pm 0.08$ & 0.52 & 98.43 \\
\hline F9 & $248.70 \pm 1.38$ & $5.80 \pm 0.09$ & 0.48 & 98.68 \\
\hline
\end{tabular}

*All values are expressed as mean \pm SD, $\# \mathrm{n}=20 ;{ }^{*} \mathrm{n}=6$.

\section{In vitro dissolution study}

Metoclopramide release from the matrix tablets was studied for the first two hours in $\mathrm{p}^{\mathrm{H}} 1.2$ buffer and the next ten hours in $\mathrm{p}^{\mathrm{H}} 6.8$ phosphate buffer. Total nine formulations were made with xanthan gum, ethyl cellulose and combination of xanthan gum and ethyl cellulose in different ratios i. e 1:1,1:1.5 and 1:2. The release profiles are given in fig. 1.
Metoclopramide release from all the matrix tablets was dependent on the percent of release retardant contained in the tablet. As the percent of the polymer was increased, release was decreased. Ethyl cellulose could not control the release of metoclopramide from the tablets because when a matrix is composed of a water-soluble drug and a water-insoluble polymer, drug release occurs by dissolution of the active 
ingredient through capillaries. Xanthan gum could control the release of metoclopramide hydrochloride up to $12 \mathrm{~h}$ because of its high molecular weight. These results indicate that xanthan gum has a higher drug retarding ability than ethyl cellulose. Presence of xanthan gum alone and in combination retarded the initial release of drug from the tablets due to high swelling.

The release data of matrix tablets were fitted into various mathematical models (zero order, first order, higuchi, and Peppas) to evaluate the kinetics and mechanism of drug release from the tablets. The model that best fits the release data is selected based on the correlation coefficient value in various models. The model that gives high $\mathrm{R}^{2}$ value considered as the best fit of the release data. The $\mathrm{R}^{2}$ values in zero, first order, higuchi peppas, and hixon-crowel models are given in table 4 .

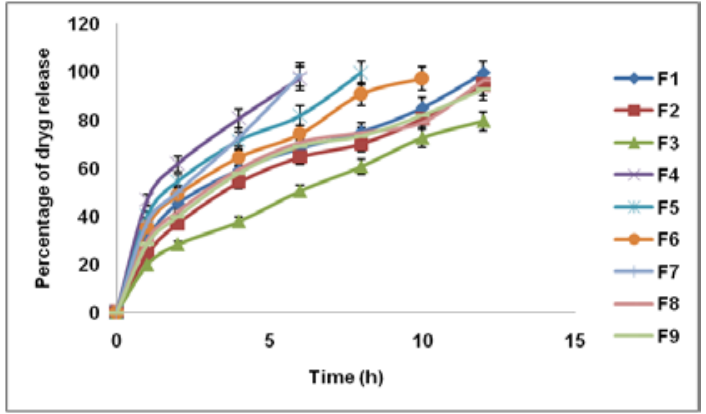

Fig. 1: Comparative in vitro dissolution profile of all the formulations mean $\pm S D, n=3$

Table 4: Release kinetics of metoclopramide hydrochloride matrix tablets

\begin{tabular}{|c|c|c|c|c|c|c|}
\hline \multirow[t]{2}{*}{ Formulation } & \multirow[t]{2}{*}{ Zero-order } & \multirow[t]{2}{*}{ First order } & \multirow[t]{2}{*}{ Higuchi } & \multicolumn{2}{|c|}{ Peppas } & \multirow[t]{2}{*}{ Hixon-crowel } \\
\hline & & & & $\mathbf{R}^{2}$ & $\mathbf{n}$ & \\
\hline F1 & 0.894 & 0.975 & 0.989 & 0.989 & 0.43 & 0.883 \\
\hline $\mathrm{F} 2$ & 0.923 & 0.897 & 0.993 & 0.991 & 0.52 & 0.956 \\
\hline F3 & 0.963 & 0.985 & 0.987 & 0.990 & 0.56 & 0.990 \\
\hline $\mathrm{F} 4$ & 0.853 & 0.946 & 0.992 & 0.999 & 0.40 & 0.977 \\
\hline F5 & 0.888 & 0.973 & 0.986 & 0.982 & 0.40 & 0.862 \\
\hline F6 & 0.920 & 0.860 & 0.988 & 0.981 & 0.46 & 0.938 \\
\hline F7 & 0.945 & 0.847 & 0.993 & 0.986 & 0.53 & 0.943 \\
\hline F8 & 0.918 & 0.872 & 0.994 & 0.995 & 0.48 & 0.948 \\
\hline F9 & 0.927 & 0.904 & 0.995 & 0.996 & 0.50 & 0.961 \\
\hline
\end{tabular}

The results given in table 3 indicated that the drug release from the matrix tablets followed zero order kinetics. To evaluate the drug release mechanism from the matrix tablets plots of percent drug released verses square root of time as per Higuchi's equation were constructed. These plots were found to be linear with all the tablets with correlation coefficient values in the range 0.986 to 0.995 indicating that the drug release from the tablet was diffusion controlled. When the release data were analyzed as per peppas equation, the release exponent $n$ value was less than 0.89 with all the tablets indicating Fickian diffusion might be the mechanism for the drug release from the matrix tablets.

\section{Compatibility studies}

From the FTIR studies shown in fig 2, it is very clear that there are no interactions between drug and excipients. All the peaks responsible for the active functional groups were present in the best formulation (F2). The characteristic and observed peaks are mentioned in table 5 .

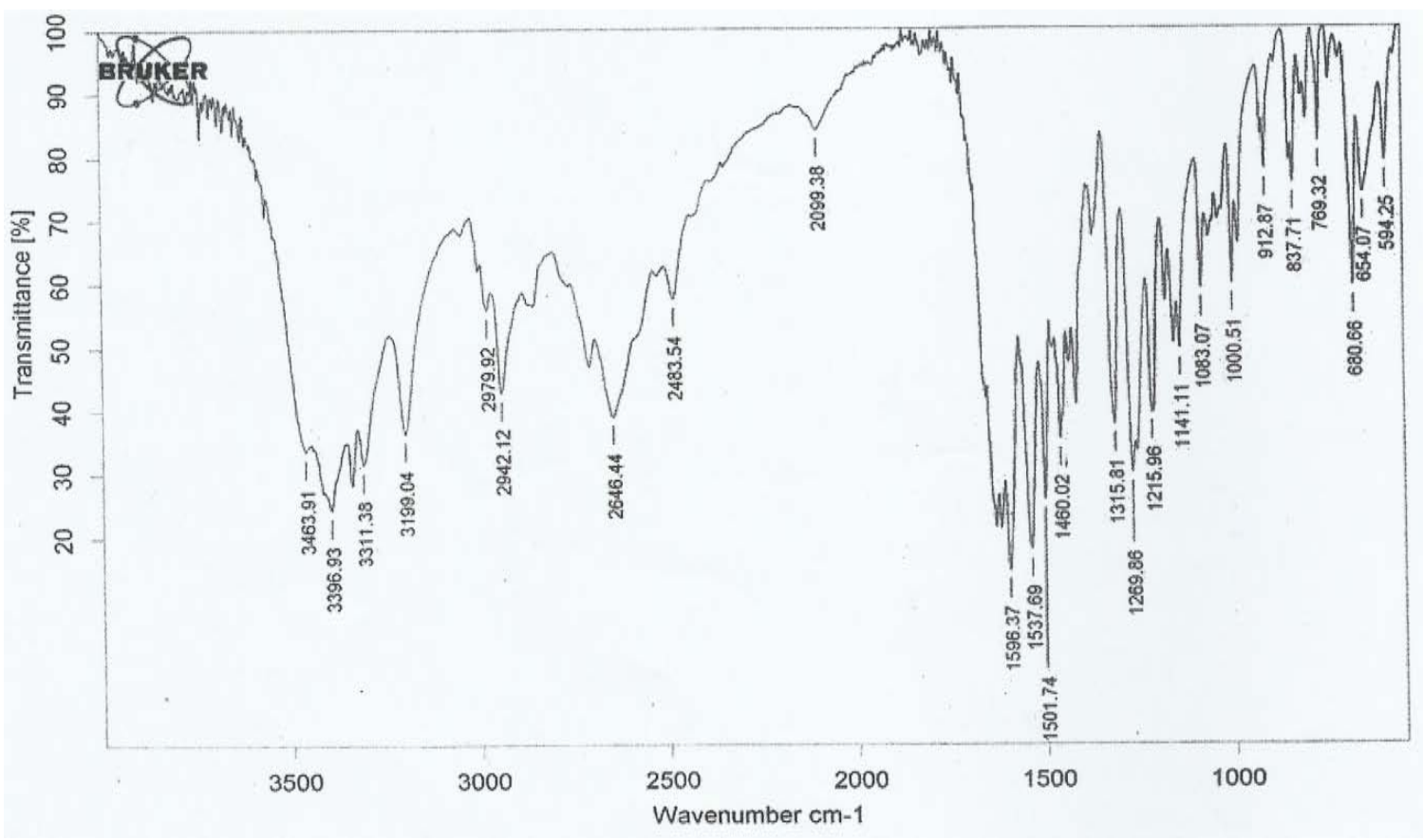

Fig. 2(a): FTIR spectrum of pure metoclopramide hydrochloride 


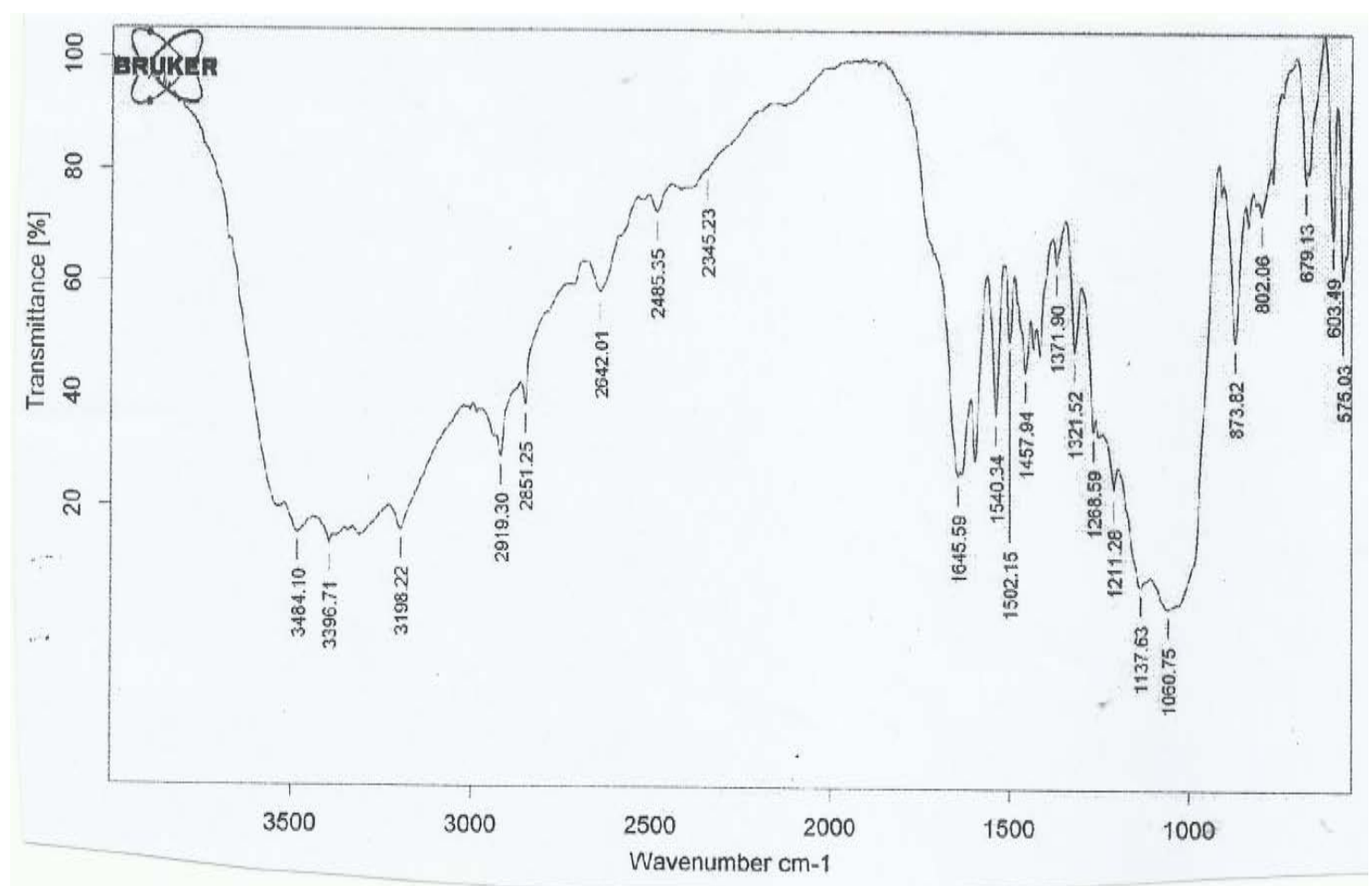

Fig. 2(b): FTIR spectrum of metoclopramide hydrochloride matrix tablet (F2)

Table 5: Data of FT-IR spectra of pure and best formulation

\begin{tabular}{llll}
\hline Functional group & Characteristic peak cm-1 & Observed peaks-pure drug cm-1 & Observed peaks-best formulation cm-1 \\
\hline N-H (stretching) & 3500 (asymmetric) & 3463 & 3484 \\
& 3400 (symmetric) & 3396 & 3396 \\
$\mathrm{OCH}_{3}$ & $1270-1230$ & 1269 & 1268 \\
$\mathrm{~N}-\mathrm{H}$ (bending) & $1650-1580$ & 1596 & 1645 \\
$\mathrm{C}-\mathrm{N}$ (stretching) & $1220-1020$ & 1215 & 1211 \\
$\mathrm{C}=\mathrm{C}$ & 1500 & 1501 & 1502 \\
\hline
\end{tabular}

\section{CONCLUSION}

Sustained release matrix tablets of metoclopramide hydrochloride were prepared using different ratios of xanthan gum and ethyl cellulose by direct compression method. The results of the present study demonstrate that the ethyl cellulose alone could not control the metoclopramide release effectively for $12 \mathrm{~h}$, whereas when combined with xanthan gum, it could control the release of metoclopramide from their matrices. It is concluded that the sustained release of metoclopramide hydrochloride over a period of $12 \mathrm{~h}$ was obtained with formulation (F-2) containing xanthan gum. The mechanism of drug release from the matrix tablets was found to be diffusion controlled i. e fickian diffusion. Sustained release matrix tablets of metoclopramide hydrochloride can be expected to reduce the frequency of administration and decrease the dose-dependent side effects associated with repeated administration of conventional metoclopramide hydrochloride tablets.

\section{ACKNOWLEDGMENT}

The authors are thankful to the principal and management of Anurag Pharmacy College, for providing necessary facilities to carry out this work.

\section{AUTHORS CONTRIBUTIONS}

All the authors have contributed equally

\section{CONFLICT OF INTERESTS}

Declared none

\section{REFERENCES}

1. Patel MH, Ashok KP, Suresh K, Someshwara RB. Design and evaluation of controlled release matrix tablets of metoclopramide hydrochloride using hydrophilic polymers. Int J Curr Pharma Res 2012;4:64-9.

2. Paloma F, Cristiana P, Jose LL, Gloria F. In vitro release of metoclopramide from hydrophobic matrix tablets. Influence of hydrodynamic conditions on kinetic release parameters. Chem Pharm Bull 2001;49:1267-71.

3. Mannujan N, Saiful MD, Fatima N, Syed SH. Development of sustained-release preparations of metoclopramide hydrochloride based on the fatty matrix. Dhaka Univer J Pharm Sci 2012;11:129-36.

4. Neha SL, Neelam S, Yasir M. Sstained release solid dispersion of metoclopramide hydrochloride: formulation, evaluation, and pharmacokinetic studies. J Appl Pharma Sci 2015;5:55-65.

5. Sayed AR, Gamal MM, Mahmuod EB. Preparation and comparative evaluation of sustained release metoclopramide hydrochloride matrix tablets. Saudi Pharm J 2009;17:283-8.

6. Sateesh KV, Prabhakar RV. Colon specific controlled release matrix tablets of flurbiprofen: development and characterization. Asian J Pharm Clini Res 2012;5:92-6.

7. Ranjith PS, Ratna KT, Satyajit P. Formualtion development and evaluation of sustained release ibuprofen tablets with acrylic polymers and HPMC. Int J Pharma Pharma Sci 2016;8:131-5.

8. Sabyasachi M, Santanu K, Somasree R, Biswanath S. Development and evaluation of xanthan gum facilitated ethyl cellulose microsponges for controlled percutaneous delivery of diclofenac sodium. Acta Pharm 2011;61:257-70. 
9. Geeta MP, Madhabhai MP. Compressed matrix dual-component vaginal drug delivery system containing metoclopramide hydrochloride. Acta Pharm 2009;59:273-88.

10. Raghavendra Rao NG, Prasanna KR, Sanjeev NB. Review on matrix tablets as sustained release. Int J Pharma Res Alli Sci 2013;2:1-17.

11. Wadher KJ, Ghodasare $\mathrm{Ch}$ and Umekar MJ. Formulation and evaluation of controlled release matrix tablets using eudragit RSPO and gum copal. Int J Pharm and chemical Res 2017; 3: 1-7.

12. Jaya $S$ and Amala V. Formulation and invitro evaluation of oral disintegrating tablets of amlodipine besylate. Int J Appli Pharmaceutics 2019; 11:49-54

13. Jaya S, Chowdary KPR and Rajeswara RP. Effect of superdisintegrants and solubilizers on the disoolution rate and dissolution efficiency of ritonavir. Int Res J Pharm Appl Sci 2012; 2: 224-9.

14. Jaya S, Chowdary KPR and Rajeswara RP. Enhancement of dissolution rate and formulation development of ritonavir tablets by solid dispersion technologies. Int J Pharma Therape 2013; 4: 51-8.

15. Chang R, Robinson JR. Sustained release from tablets and particles through coating In: H.A. Libreman, L. Lachman and J.B. Schwart (Eds), Pharmaceutical dosage forms: Tablets, 2 nd Edn. Vol.3, Marcel Dekker, 1990.199-302.

16. Suvakanta D, Narasimha MP, Lilakanta $n$ and Prasanta C. Kinetic modeling on drug release from controlled drug delivery systems. Acta Palaniae Pharm Drug Res 2010; 67:217-23. 